\title{
Análise dos fatores relacionados aos acidentes de trabalho com perfuro cortantes em uma instituição hospitalar
}

\section{Rodrigo Abreu Barbosa} Rodrigoab05@yahoo.com.br
Faculdade Sagrada Família (FASF), Faculdade Sagrada Familia
Ponta Grossa, Paraná, Brasil

\section{Rudy de Barros Ahrens} coordfasf@gmail.com

Faculdade Sagrada Família (FASF), Ponta Grossa, Paraná, Brasil

\author{
RESUMO
}

O presente estudo analisou os acidentes de trabalho de janeiro de 2014 a setembro de 2017, principalmente os ocorridos com instrumentos perfuro cortantes, na empresa objeto de estudo, um hospital privado localizado no município de Ponta Grossa no Paraná, contando atualmente com 163 funcionários ativos, 75 ligados diretamente à área assistencial de enfermagem, divididos em 14 enfermeiros, 58 técnicos de enfermagem, e 3 auxiliares de enfermagem. Na coleta de dados foram utilizados os históricos sobre os acidentes de trabalho e informações fornecidas pela empresa acerca destes acidentes, e aplicado questionário destinado a levantamento de dados complementares sobre os acidentes, na tentativa de identificação de fatores e processos envolvidos nos acidentes. Nos resultados encontrados através do questionário, temos apontamentos quanto ao cansaço e stress acumulado devido a dupla jornada de trabalho, algo comum entre a categoria de profissionais do setor de enfermagem, além da alegação de baixa remuneração por grande parte dos profissionais consultados.
\end{abstract}

PALAVRAS-CHAVE: Acidentes de Trabalho. Clima Organizacional. Enfermagem. 


\section{INTRODUÇÃO}

A preocupação com a segurança e bem estar dos colaboradores é cada vez mais evidente dentro das empresas nos mais diversos ramos de atuação, e não é diferente na área de Atenção à Saúde, em principal nas Instituições Hospitalares, visto o risco de contaminação com doenças infectocontagiosas, e à subestimação deste por parte dos profissionais da área da saúde que muitas vezes enxergam suas atividades como corriqueiras e inofensivas, ainda que sejam primordiais na preservação da vida dos pacientes, e dos próprios colaboradores que passam o dia em atendimento à pacientes que muitas vezes não possuem seu histórico médico dentro da instituição. As chamadas infecções hospitalares são ainda uma grande ameaça a estes profissionais, ocorrendo em 3\% a 15\% dos pacientes internados, aumentando em média cinco a dez dias ao período de internação, além dos custos hospitalares (HINRICHSEN, 2004).

As instituições passaram a ter um papel cada vez mais determinante na prevenção dos acidentes, atuando cada vez mais ativamente e desempenhando seu papel como órgão de prevenção, investindo em educação continuada, dispondo de infraestrutura adequada ao desempenho de suas atividades laborais, além de prover materiais e equipamentos de qualidade e na quantidade apropriada (BOLICK et al., 2000).

Um dos problemas gerais nos casos de acidentes de trabalho é identificar os fatores que foram responsáveis diretamente pelo acidente, neste caso, os acidentes com perfuro cortantes. $\mathrm{O}$ objetivo geral deste estudo é descobrir estes principais fatores responsáveis nos acidentes na empresa objeto de estudo, e são ainda objetivos específicos:

a) relacionar os acidentes ás rotinas de treinamentos, (Equipamento de Proteção Individual (EPI's) e equipamentos;

b) avaliar possíveis fatores psicológicos relacionados aos acidentes;

c) associar causas dos acidentes à resistência de mudança na cultura organizacional;

Qualquer empresa ainda que pense em reduzir custos com certeza investirá em segurança, pois os acidentes provocam perdas financeiras para o acidentado, para a sua família, para a organização e para a sociedade, e ainda que o seguro de acidentes de trabalho cubra os gastos com despesas médicas e indenizações aos acidentados, não repõe a capacidade humana para o trabalho e nem a integridade física às pessoas acidentadas, tornando a situação irreparável (CHIAVENATO, 2008).

Com tantas variáveis oferendo risco às rotinas funcionais e ainda tantos agentes externos de ameaça, qualquer estudo na tentativa de identificação de possíveis fatores envolvidos nos acidentes de trabalho e minimização dos riscos se faz necessário e um possível auxiliar nesta luta de prevenção.

\section{REFERENCIAL TEÓRICO}


Para Chiavenato (2008) fazer do ambiente um lugar agradável para se trabalhar tornou-se uma verdadeira obsessão para as empresas, um ambiente agradável facilita o relacionamento interpessoal e melhora a produtividade, bem como reduz acidentes, doenças, absenteísmo e rotatividade de pessoal.

[...] os riscos de saúde como riscos físicos e biológicos, tóxicos e químicos, bem como condições estressantes de trabalho podem provocar riscos no trabalho. $\mathrm{O}$ ambiente de trabalho em si também pode provocar doenças. Uma definição mais ampla de saúde é o estado físico, mental e social de bemestar. Essa definição enfatiza as relações entre corpo, mente e padrões sociais. A saúde de uma pessoa pode ser prejudicada por doenças, acidentes ou estresse emocional (CHIAVENATO, 2008, p.471)

Um colaborador excelente e competente, mas deprimido e com baixa autoestima, pode ser tão improdutivo quanto um colaborador doente e hospitalizado, e neste contexto temos o estresse como grande inimigo no ambiente de trabalho.

Chiavenato (2008) enfoca que a organização pode colaborar na identificação e redução do estresse no trabalho, monitorando os colaboradores para identificação de sintomas e ainda prevenir fontes organizacionais de estresse, refinando os procedimentos e adequando pessoas e cargos, bem como propor um planejamento de carreiras.

Tão importante quanto resolver problemas de stress e desmotivação em sua equipe de trabalho, é preveni-los. Uma empresa que não presa pela manutenção da excelência em seu clima organizacional fatalmente terá problemas de queda de produção e qualidade em seu meio. Hoje temos muitas ferramentas disponíveis tanto para avaliação e mensuração do clima organizacional, quanto à implantação de programas de qualidade de vida no trabalho, transformando o bem-estar do colaborador em prioridade.

\section{SAÚDE E SEGURANÇA NO TRABALHO}

Apesar do consenso geral quanto ao fato de que Sistemas de Saúde e Segurança do Trabalho são fundamentais na criação de ambientes de trabalho mais seguros e saudáveis, ainda não se tem um consenso quanto à um modelo ideal de sistema de Saúde e Segurança. As organizações utilizam modelos diferentes, adequando-os às necessidades de cada empresa, obedecendo à normas específicas de cada segmento. A visão preventiva planejada refere-se ao controle, através de métodos avaliativos dos acidentes. Estes eventos muitas vezes, são associados à inúmeras causas, análises objetivas e rápidas podem levar à conclusão de que a causa pode estar nos fatores humanos ou em algum problema técnico (CAMARGO, 2011).

Um programa de segurança no trabalho requer algumas etapas: eleger indicadores e estatísticas de acidentes, desenvolver sistemas de relatórios e providências, regras e procedimentos de segurança e um sistema de recompensa aos agentes pela administração eficaz da função da segurança; e elenca as principais medidas preventivas contra acidentes: Educação: criar a consciência da segurança através de comunicação eficaz; Treinamento: incorporar medidas de 
prevenção em processos de aprendizagem; Engenharia: desenho de equipamentos e tarefas prevenindo acidentes; Mapeamento de riscos: identificar e eliminar áreas de riscos; Proteção: incluindo equipamentos de proteção e manutenções preventivas; e Regras de reforço: regras e regulamentos constantemente reforçados (CHIAVENATO, 2008).

Programas de Segurança e Prevenção funcionam muito melhor com aceitação e colaboração de todos os funcionários, principalmente quando formulado e revisado em conjunto com ambas as partes, empregador e empregado, lado a lado. Uma das formas de manter o foco e atenção dos colaboradores são os sistemas de recompensa, enaltecendo e reconhecendo as boas atitudes e condutas de segurança, o que é confundido constantemente com penalidades, infelizmente.

\section{SEGURANÇA NO TRABALHO EM INSTITUIÇÕES HOSPITALARES}

Dentro das Instituições Hospitalares possuir uma rotina de treinamentos e segurança, além de materiais e equipamentos de qualidade deixou de ser um diferencial há muito tempo, e não passa do mínimo para assegurar a segurança básica de seus colaboradores, pois o trabalho de enfermagem em instituições hospitalares acontecem 24 horas por dia de forma contínua na assistência aos pacientes, e na maioria das vezes os funcionários estão em contato com pacientes agitados, agressivos ou ansiosos, além do fato de terem de manusear agulhas, lâminas de bisturi, tesouras, vidros, além de outros instrumentos perfurantes e cortantes. A Norma Regulamentadora no 32 (NR-32, 2009) de Saúde e Segurança no Trabalho, define materiais perfuro cortantes como aqueles utilizados na assistência à saúde que têm ponta ou gume, ou que possam perfurar ou cortar.

Muitas vezes o cuidado é extremo na hora de manusear tais equipamentos, porém após o uso, o cuidado deve ser ainda maior devido à contaminação de seringas e agulhas ao entrar em contado com o paciente, e à adição de profissionais de outras áreas nos processos envolvendo este tipo de material, em especial o serviço de higienização e limpeza, que muitas vezes recebe treinamento e educação continuada específica na coleta e retirada deste material, ficando dependente do correto descarte e manuseio dos profissionais da enfermagem. Neste contexto a Agência Nacional de Vigilância Sanitária (ANVISA, 2004) expediu a Resolução RDC no 306, que dispõe sobre o Regulamento Técnico para o gerenciamento de resíduos de serviço de saúde, onde são regulamentadas normas e rotinas no manejo, segregação, acondicionamento e coleta de materiais, inclusive de materiais perfuro cortantes. Tal resolução padronizou as caixas de acondicionamento de perfuro cortante, e limitava o uso dessa caixa a $2 / 3$ de sua capacidade, ou quando o nível de preenchimento ficar a cinco centímetros de distância da boca do recipiente, além de proibir o esvaziamento e/ou reaproveitamento, o que impactou na diminuição dos acidentes de trabalho envolvendo a coleta destes materiais, que muitas vezes transpassavam o recipiente, por estarem acomodados de forma incorreta ou muito cheios.

É papel das instituições disponibilizar recipientes resistentes e impermeáveis em locais de fácil acesso para o depósito de materiais perfuro cortantes, e 
fornecer aos trabalhadores seringas sem agulhas ou com agulhas retráteis, apesar do elevado custo (BOLICK et al., 2000). Neste sentido a resolução № 306 da ANVISA também estipulou a proibição no reencape e separação manual das agulhas com seringas descartáveis, o que ocasionava muitos acidentes após o contato com o paciente, que deixou de ocorrer após serem desprezadas de forma conjunta, sem reencape nem desconexão.

Tem-se ainda a portaria no 939 de 18 de Novembro de 2008 do Ministério do Trabalho e Emprego (MTE, 2008) que impõe a substituição dos materiais perfuro cortantes por outros que contenham dispositivo de segurança no prazo máximo de 24 meses, porém revogada através da portaria no 1748 da mesma entidade em 30 de Agosto de 2011 (MTE, 2011), que revoga a obrigatoriedade da implantação bem como seu prazo devido ao custo elevado dos dispositivos, e ausência de número suficientes de fornecedores e treinamentos específicos, porém estipula que os empregadores deverão implementar Plano de Prevenção de Riscos de Acidentes com materiais perfuro cortantes, o que mostra a preocupação com um dos principais agentes causadores de acidentes de trabalho da área da Saúde. Para a Norma Regulamentadora (NR-32, 2009) o dispositivo de segurança é um item integrado a um conjunto, do qual faça parte o elemento perfuro cortante ou uma tecnologia capaz de reduzir o risco do acidente, seja qual for o mecanismo de ativação do mesmo.

Além de tantos fatores adversos, existem também os fatores psicológicos envolvendo risco aos indivíduos, pois a maioria dos colaboradores da área da saúde acumulam dupla jornada devido ao déficit salarial da categoria, ficando à deriva de stress e cansaço acumulados, mudando muito sua postura em relação às suas atividades normais, aliado ao fato da dificuldade em se manter um bom clima organizacional em entidades hospitalares devido ao grau de insalubridade e à própria natureza de serviço, torna um desafio constante na vida destes trabalhadores.

\section{METODOLOGIA}

Este estudo caracterizou-se em forma de pesquisa exploratória, o que permite uma maior aproximação entre pesquisador e tema, geralmente este pouco explorado, permitindo o aprimoramento de ideias e construindo hipóteses.

As pesquisas exploratórias têm como principal finalidade desenvolver, esclarecer, e modificar conceitos e ideias, tendo em vista a formulação de problemas mais precisos ou hipóteses pesquisáveis para estudos posteriores. De todos os tipos de pesquisas estão são as que apresentam menor rigidez no planejamento e habitualmente envolvem levantamento bibliográfico e documental, entrevistas não padronizadas e estudos de caso. Procedimentos de amostragem e técnicas quantitativas de coleta de dados não são costumeiramente aplicados nestas pesquisas (GIL, 2008, p. 27).

Gil (2008) define pesquisa bibliográfica por aquelas desenvolvidas a partir de material já elaborado, e elabora que parte dos estudos exploratórios podem ser 
definidos como pesquisas bibliográficas, atribuindo vantagem ao investigador e permitir a cobertura de uma gama de fenômenos pesquisada indiretamente. Gil (2008) assimila ainda as pesquisas bibliográficas e documentais, diferenciando as documentais por valerem-se de materiais que não receberam ainda um tratamento analítico, ou ainda que podem ser reelaborados de acordo com a pesquisa.

A principal vantagem da pesquisa bibliográfica reside no fato de permitir ao investigador a cobertura de uma gama de fenômenos muito mais ampla do que aquela que poderia pesquisar diretamente. Esta vantagem se torna particularmente importante quando o problema de pesquisa requer dados muito dispersos pelo espaço. [...] A pesquisa bibliográfica também é indispensável nos estudos históricos, em muitas situações, não há outra maneira de conhecer os fatos passados senão com base em dados secundários (GIL, 2008, p. 50).

A característica da pesquisa documental é que a fonte de coleta de dados está restrita a documentos, constituídas por fontes primárias, do momento em que o fato ou fenômeno ocorre, ou posteriormente (LAKATOS e MARCONI, 2003).

Lakatos e Marconi (2003) definem questionário como um instrumento de coleta constituído por uma série de perguntas ordenadas, e orientam o envio de uma nota ou carta explicando a natureza da pesquisa. Atribuem ainda uma média de $25 \%$ de devolução, e apontam vantagens (economia de tempo, abrangência, economia pessoal, respostas rápidas e precisas e segurança), e desvantagens (poucos questionários devolvidos, perguntas em branco, dificuldade de compreensão e atraso na devolução). Ainda de acordo com Lakatos e Marconi (2003) as perguntas devem ser elaboradas e organizadas por tipo, ordem e grupos, e além do processo ser longo e complexo deve-se tomar cuidado quanto à extensão e finalidade; se for muito longo causará fadiga e desinteresse; se curto demais, corre o risco de não oferecer informações suficientes.

As questões a serem aplicadas devem ser elaboradas de forma precisa, para que o entendimento do entrevistado ocorra sem dificuldades, questões abertas devem ser evitadas, pois pela questão do tempo disponível, as respostas tem probabilidade de mudança de significado, e as questões devem ser distribuídas de maneira a favorecer o rápido entendimento das questões, para melhor engajamento do respondente, além da manutenção de seu interesse. (GIL, 2008).

Para obter-se a atualização dos casos de acidentes de trabalho e a formatação das tabelas apresentadas na seção 4.1 da análise de dados, usamos o banco de dados da instituição, além de informações de controle dos setores se Segurança do Trabalho e Recursos Humanos, também demonstradas na seção de análise de dados.

Temos ainda a informação complementar obtida com base nos questionários aplicados, que serviu para os resultados apresentados na seção 4.2 da análise de dados. Foram entregues 75 questionários aos coordenadores do departamento de enfermagem, visando atingir todos os funcionários lotados na enfermagem da instituição de todos os turnos de trabalho, dos quais retornaram preenchidos 55 questionários, indicando uma taxa de $73,33 \%$ de devolução dos questionários, que podemos considerar uma ótima taxa, visto que dentre os 20 questionários 
não preenchidos temos 06 funcionários que se encontravam em férias e 02 funcionários em licença médica.

\section{ANÁLISE DOS DADOS}

O campo de estudo foi a instituição Hospital Vicentino, hospital privado localizado no município de Ponta Grossa no Paraná, contando atualmente com 163 funcionários ativos, destes apenas 75 são ligados diretamente à área assistencial de enfermagem, divididos em 14 enfermeiros, 58 técnicos de enfermagem, e 3 auxiliares de enfermagem. 0 número reduzido na categoria de auxiliares de enfermagem se deve ao fato do curso específico de formação não existir mais, sendo substituído aos poucos pelo curso técnico de enfermagem. Vale ressaltar que dentro da instituição não existe diferenciação de tarefas entre os profissionais auxiliares e técnicos de enfermagem, porém há divisão do piso salarial da função, observado na atual Convenção Coletiva da categoria.

\section{ANÁLISE DOS ACIDENTES}

A Tabela 1 apresenta o quadro geral de funcionários da Instituição, e os acidentes de trabalho analisados e separados por Setor de Trabalho, mostrando a grande predominância do departamento de enfermagem nos acidentes. No setor de enfermagem estão incluídas as categorias de Enfermeiro, Técnico de Enfermagem e Auxiliar de Enfermagem, pelo contato direto com o paciente.

Tabela 1 - Distribuição dos acidentes por Setor de Trabalho

\begin{tabular}{|c|c|c|c|c|}
\hline \multirow{2}{*}{ Setores } & \multicolumn{2}{|c|}{ Funcionários Total } & \multicolumn{2}{|c|}{ Acidentes de Trabalhc } \\
\hline & Qtade & $\%$ & Qtade & $\%$ \\
\hline Administração & 51 & $31,29 \%$ & 2 & $3,45 \%$ \\
\hline Enfermagem & 75 & $46,01 \%$ & 39 & $67,24 \%$ \\
\hline Serv. de Proc. de Roupas & 3 & $1,84 \%$ & 2 & $3,45 \%$ \\
\hline Serv. de Nutrição & 15 & $9,20 \%$ & 4 & $6,90 \%$ \\
\hline Serv. de Limpeza & 16 & $9,82 \%$ & 8 & $13,79 \%$ \\
\hline $\begin{array}{ll}n & \text { Serv. de Manutenção } \\
+\end{array}$ & 3 & $1,84 \%$ & 3 & $5,17 \%$ \\
\hline TOTAL & 163 & $100 \%$ & 58 & $100 \%$ \\
\hline
\end{tabular}

Fonte: Elaborado pelos Autores (2017).

Parte da concentração dos acidentes nas categorias de enfermagem são explicadas pelo risco natural da prestação de assistência de enfermagem e exposição à riscos naturais, tais como os próprios perfuro cortantes. Proporcionalmente ligado ao risco pelo contato direto ao perfuro cortante segue o setor de Higiene Limpeza, muitas vezes exposto no momento da coleta do material. Os hospitais são considerados locais tipicamente insalubres, pois propiciam quase a totalidade de seus trabalhadores á inúmeros riscos, ainda que em alguns serviços ocorram riscos maiores, direta ou indiretamente todos os trabalhadores são expostos à riscos físicos, químicos, fisiológicos, psíquicos, mecânicos e biológicos. (LAURELL e NORIEGA, 1989). 
Tabela 2 - Causas dos Acidentes de Trabalho

\begin{tabular}{ccc} 
Causa & \multicolumn{2}{c}{ Acidentes de Trabalho } \\
Perfuro Cortante & Qtade & $\%$ \\
Queda & 18 & $31,03 \%$ \\
Contusão & 14 & $24,15 \%$ \\
Entorse & 10 & $17,24 \%$ \\
Químico & 3 & $5,17 \%$ \\
Biológico & 3 & $5,17 \%$ \\
Corte & 2 & $3,45 \%$ \\
Ergonômico & 2 & $3,45 \%$ \\
Queda de Objeto & 2 & $3,45 \%$ \\
Escoriação & 2 & $3,45 \%$ \\
Queimadura & 1 & $1,72 \%$ \\
TOTAL & 1 & $1,72 \%$ \\
\hline
\end{tabular}

Fonte: Elaborado pelos Autores (2017).

A Tabela 2 separa os acidentes quanto à causa dos mesmos, a instituição efetua a divisão dos acidentes quanto à: Perfuro Cortante (acidentes com materiais pontiagudos, como agulhas, seringas, tesouras, bisturis e demais objetos pontiagudos); Queda (ocorridos com queda do funcionário, em mesmo nível ou em altura); Contusão (onde o funcionário tem a contusão devido à uma lesão ou pancada); Entorse (onde algum membro fica preso ocorrendo entorse/estiramento); Químico (acidentes envolvendo algum agente ou produto químico); Biológico (envolvendo materiais biológicos, na maioria das vezes com o contato de sangue ou secreções em contato com a mucosa do funcionário); Corte (acidentes com corte em portas e equipamentos); Ergonômico (acidentes posturais, em grande maioria ao levantar pacientes de forma não adequada); Queda de Objetos (caracterizados pela queda de materiais e equipamentos atingindo o funcionário); Escoriação (caracterizados por lesão à pele, nos casos analisados foram decorrentes de acidentes de trânsito/trajeto) e Queimadura (ocasionados por lesão à pele decorrente de queimadura, nos casos analisados ocorrido por óleo fervente). A Tabela 2 ainda nos mostra as maiores incidências nos acidentes com perfuro cortantes $(31,03 \%)$ e queda $(24,15 \%)$, que somados ultrapassam mais da metade do total de acidentes do período, mostrando risco elevado envolvendo materiais perfuro cortantes e trabalhos com elevação de nível.

A Tabela 2 ainda chama a atenção pela alta incidência dos acidentes com queda, contusão e entorse, que somados chegam à um total alarmante de $46,56 \%$ dos acidentes. Muitos destes acidentes estão relacionados à estrutura física como por exemplo desnivelamento em calçada, piso irregular, falta de espaço adequado para desenvolver certas atividades e superfícies molhadas e escorregadias, muitos problemas estruturais ou falta de adequação na construção de novas instalações exigem grande custo e esforço para posterior adequação. 
Um dos problemas gerais no âmbito hospitalar e foco de atenção dos principais programas de qualidade é a dificuldade na adequação da estrutura física. Muitos problemas podem ser evitados no caso de um projeto de construção e/ou ambientação com integração entre arquitetos, engenheiros, médicos, enfermeiros e administradores trabalhando junto à Comissão de Infecção Hospitalar $(\mathrm{CClH})$, observando os fatores de riscos existentes e a formação de recursos humanos. (HINRICHSEN, 2004).

Tabela 3 - Acidentes com material perfuro cortante por ano

\begin{tabular}{ccc} 
Ano do Acidente & \multicolumn{2}{c}{ Acidentes com Perfuro } \\
& Qtade & $\%$ \\
2014 & 9 & $50,00 \%$ \\
2015 & 6 & $33,33 \%$ \\
2016 & 2 & $11,11 \%$ \\
2017 & 1 & $5,56 \%$ \\
TOTAL & $\mathbf{1 8}$ & $\mathbf{1 0 0 \%}$ \\
\hline
\end{tabular}

Fonte: Elaborado pelos Autores (2017).

A Tabela 3 mostra todos os acidentes com perfuro cortante separados pelo ano em que ocorreu o acidente. É evidente a diminuição após a RDC no 306 (ANVISA, 2004) citada anteriormente e uma campanha massiva na adequação e controle de acidentes com materiais de perfuro cortante, aliada à uma política de educação realizada na instituição. Os acidentes diminuíram gradativamente conforme medidas corretivas eram tomadas quanto à ocorrência do acidente, muitos acidentes ocorriam somente após o atendimento e tratamento dos objetos perfuro cortantes, seja no descarte dos objetos ou ainda no tratamento dos objetos após o descarte, e neste sentido foram criados manuais de normas e rotinas padrões na instituição, principalmente de descarte, acondicionamento e transporte dos materiais perfuro cortantes, sofrendo atualizações periódicas e evoluindo até se tornar parte do programa de gerenciamento de resíduos sólidos de saúde da instituição. Os resíduos sólidos de serviços de saúde (RSS) são gerados por prestadores de assistência médica, e possuem potenciais riscos em função da presença de materiais biológicos, produtos químicos e objetos perfuro cortantes contaminados. Os resíduos de saúde compreendem menos de $1 \%$ do volume total dos resíduos municipais e sua taxa de geração depende do tipo de serviço, número de atendimentos, recursos humanos e percentual de leitos ocupados. (HINRICHSEN, 2004).

\section{QUESTIONÁRIO APLICADO}

O questionário encontrado no apêndice deste estudo foi aplicado durante o mês de dezembro de 2017, no período entre os dias 11 a 20, devido à rotatividade de folgas de funcionários e troca de horários entre os períodos matutino, vespertino e noturno. Foram entregues 75 questionários a fim de atingir $100 \%$ dos colaboradores de todos os setores de enfermagem da instituição, destes retornaram preenchidos 55 questionários, dos quais 31 identificados com nome e setor, e 24 sem identificação, já que o questionário apontava como dado opcional. Este percentual atingido nos questionários retornados preenchidos $(73,33 \%)$ é satisfatório, visto que junto aos questionários 
não preenchidos ainda temos 06 funcionários que estavam em férias e 02 funcionários ausentes por motivos médicos, com a pesquisa atingindo assim 82,09\% dos funcionários que estavam disponíveis nos setores.

Dos colaboradores que responderam o questionário, 17 já haviam sofrido algum tipo de acidente de trabalho nesta ou em outra instituição, e destes acidentados, apenas 4 não acreditam que pessoas atentas e bem protegidas com EPI's podem vir a sofrer algum tipo de acidente, o que nos leva a crer que os 13 acidentados restantes de alguma forma, acreditam que estavam desatentos ou sem proteção suficiente.

A quase totalidade dos consultados (54) mostrou a importância com a conscientização dos ricos de acidentes, assinalando a opção de que estaria exposto a vir a sofrer um acidente a qualquer momento, e todos os 55 entrevistados acham que um EPI correto e com o uso adequado podem prevenir acidentes, além de 53 destes que consideram muito importante os treinamentos em rotinas de enfermagem e perfuro cortantes nesta prevenção.

Gráfico 1 - Questão 6: Quais situações você acha mais provável que ocorra um acidente?

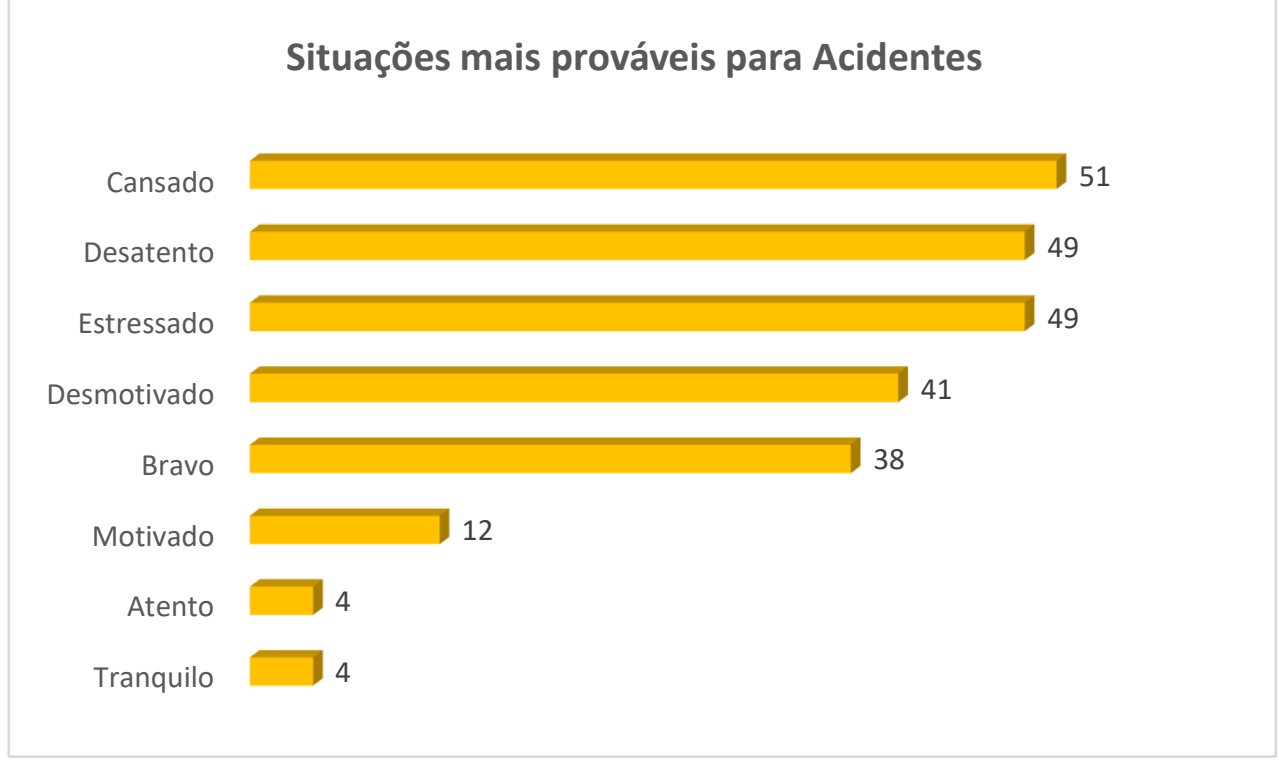

Fonte: Elaborado pelos Autores (2017).

O Gráfico 1 expressa os resultados da questão 06 "Em que situações abaixo na qual se encontra um funcionário você acha mais provável que ocorra um acidente?", e mostra novamente a ciência do risco que todos correm constantemente, ao serem marcadas todas as alternativas em alguns questionários e está ligado a questão 03 , onde foi questionado se um acidente de trabalho poderia acontecer a qualquer momento. Por amostragem podemos ver que as situações "não desejáveis" por assim dizer (Cansado, Desatento, Estressado, Desmotivado e Bravo) tiveram as maiores incidências, enquanto as situações "desejáveis" (Motivado, Atento e Tranquilo) apesar de serem marcadas, tiveram uma incidência muito menor.

Em alguns casos mais extremos de estresse o descanso não revigora por completo, e pode repor somente uma certa quantidade de energia. Algumas pessoas protelam os prazeres que a vida oferece para quando estiverem com 
estabilidade financeira, mas o que ocorre é que os bens acumulados são posteriormente gastos para cuidar de uma saúde frágil. (COSTA, 2006).

Os estados de cansaço, desatenção, estresse, desmotivação e irritação estão quase que interligados por si só, todos são foco de preocupação nas organizações e hoje muito se fala em estresse ocupacional. Selye (1965 apud Costa, 2006) classifica os sintomas do estresse em 3 fases sucessivas: alarme, resistência e esgotamento e após a fase de esgotamento constatou o surgimento de doenças como úlceras, artrites, lesões no músculo cardíaco e etc.

O mundo atual tem passado por significativas mudanças, sejam sociais, econômicas ou tecnológicas, e é evidente que todos enquanto indivíduos temos esta percepção. $O$ que não é tão evidente é o fato de que muitos indivíduos sentem tais mudanças mais que outros, e alguns ainda a veem como uma forma de pressão em si próprio, e essa rotina diária sob pressão acaba desencadeando diversos sintomas quanto ao estresse acumulado. É papel das organizações a identificação destes sintomas e trabalhar no sentido de resolução destes problemas, indicando soluções como transferências de cargo e aconselhamento, além de realizar pesquisas de atitudes identificando fontes organizacionais de estresse, refinando procedimentos de seleção e adequação entre pessoa e cargo, propondo um planejamento de carreiras em função de suas atitudes. (CHIAVENATO, 2008).

Gráfico 2 - Questão 7: Motivos causadores de Desmotivação, Stress, irritação e Cansaço?

Motivos de Desmotivação, Stress, Irritação e Cansaço

Infeliz com sua Remuneração

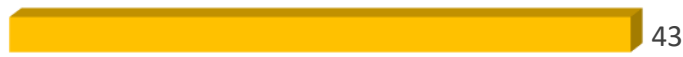

Cansado por ter 2 empregos

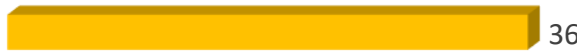

Não valorizado pelo Superior

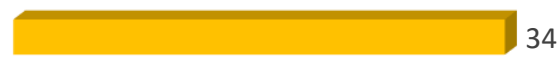

Infeliz com Colegas 43

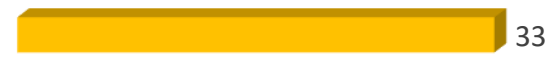

Fonte: Elaborado pelos Autores (2017).

O Gráfico 2 representa a tabulação da questão 07 "Por quais motivos você acredita que um funcionário estaria Desmotivado, Estressado, Irritado e/ou Cansado dentro da Instituição?", e aborda as situações não desejáveis da questão/gráfico anterior. Todas as opções tiveram grande incidência de respostas, com a insatisfação com a remuneração sendo o principal agente causador das situações de desmotivação, stress, irritação e cansaço.

Chiavenato (2008) define que o objetivo do salário é satisfazer as necessidades dos colaboradores, e ainda divide a remuneração total em três componentes: a remuneração básica, que inclui o salário mensal ou salário hora; os incentivos salariais que incluem bônus e participação nos resultados; e os benefícios, que incluem o seguro de vida e saúde, refeições subsidiadas, entre outros. A instituição analisada segue exatamente os padrões de salário constantes em convenção coletiva de salário, nos casos de técnicos e auxiliares 
de enfermagem, e estipula um valor de piso salarial no caso dos enfermeiros, já que esta categoria não tem sindicato profissional com abrangência neste município, e ainda é oferecido aos colaboradores o benefício de plano de saúde, com custeio de $50 \%$ pela instituição, além dos demais benefícios previstos em lei como vale transporte, refeições dentro da instituição, entre outros. Vale ressaltar que a maioria dos hospitais da região pagam uma diferenciação dos valores estipulados em convenção coletiva, justamente visando além da atratividade aos novos colaboradores, a motivação dos atuais.

Não podemos ignorar ainda as demais opções anotadas na questão (possuir dois empregos, não ser valorizado pelo superior e infeliz com seus colegas), que mesmo tendo menor incidência de respostas que a primeira opção, tiveram quantidades significativas registradas. Em especial ao item dos colaboradores possuírem dois empregos, nesta questão é interessante a comparação com a questão 09 do questionário, que aponta quantos colaboradores possuem vínculo com outra instituição além desta. Foram 19 colaboradores que dizem ter outro vínculo de trabalho, e 36 que disseram trabalhar apenas nesta instituição, exatamente o mesmo número que obtivemos apontado como causador de desmotivação, stress, irritação e cansaço ao fato do colaborador possuir dois empregos, o que pode sugerir que quase a totalidade dos funcionários que trabalham apenas nesta instituição, se sentem sobrecarregados com o fato de outros funcionários acumularem dois ou mais empregos.

Ao final do questionário todos os funcionários informaram ainda que um clima organizacional melhor pode ser capaz de prevenir acidentes, o que pode sugerir que uma tentativa de mudança no clima organizacional pode ser benéfica, e que aparentemente não encontraria muita resistência por parte dos colaboradores.

\section{CONSIDERAÇÕES FINAIS}

De acordo com as tabelas 1,2 e 3 e a análise dos acidentes de trabalho ocorridos de Janeiro de 2014 à Setembro de 2017, notamos uma diminuição significativa na incidência de acidentes de trabalho, em especial aos acidentes envolvendo perfuro cortantes, o que representa uma resposta direta à implantação de programas, campanhas e políticas de educação dentro da instituição. As rotinas de treinamento em procedimentos padrão de enfermagem, e ainda no uso correto de EPI's e equipamentos mostram-se eficientes até o período atual e tiveram sua efetividade comprovante com a aplicação do questionário, porém campanhas de segurança não tem período de validade, e devem ser praticadas e revisadas periodicamente, sob o risco das mesmas rotinas e programas de segurança perderem a efetividade ao longo do tempo.

Após a tabulação dos resultados obtidos com os questionários aplicados obtivemos algumas informações quanto aos fatores responsáveis pelos acidentes, com o cansaço, a desatenção e o stress sendo os principais deles. 0 principal motivo apontado pelos questionários é a dobra na jornada de trabalho dos funcionários da enfermagem, algo comum com a realidade financeira da profissão. Com o acumulo da jornada de trabalho em duas instituições os funcionários teriam o período matutino em uma instituição (07 às 13 hrs) e o 
período vespertino em outra (13 às $19 \mathrm{hrs),} \mathrm{mantendo} \mathrm{constante} \mathrm{e} \mathrm{diária} \mathrm{a} \mathrm{carga}$ horária de 12 horas de trabalho, montante não encontrado em nenhuma outra forma de jornada única, visto que as escalas de $12 \times 36$ horas têm um descanso de 36 horas após 12 horas de trabalho. É inegável o fato de que um funcionário tenha qualquer tipo de redução de qualidade e produtividade no trabalho, ainda que variável de indivíduo para indivíduo, quando se acumula o dobro da carga horária que costuma trabalhar, e infelizmente é uma realidade que temos em muitas áreas profissionais, devido ao grande déficit de salário em muitas categorias.

Temos ainda aliado ao fato da dobra de carga horária na função da enfermagem, a insatisfação com a baixa remuneração, apontada em mais de $78 \%$ dos questionários e muito provavelmente a principal causa da busca de um segundo emprego por parte dos colaboradores. Programas de remuneração estratégica e de cargos e salários têm se mostrado muito eficiente neste tipo de mudança nos fatores psicológicos e grande impacto na cultura organizacional, porém deve ser muito bem planejada e estruturada, além de ter resultados esperados melhores à longo prazo. Tentativas de mudança na cultura organizacional com baixos incentivos, ou ainda sem nenhum incentivo, são muito mais propensas a resistência por parte dos colaboradores, e com baixíssima estimativa de sucesso. 


\title{
Analysis of factors related to work accidents with sharp instruments in a hospital Institution
}

\begin{abstract}
The present study analyzed the occupational accidents from January 2014 to September 2017, especially those with sharp instruments, in the company under study, a private hospital located in the city of Ponta Grossa in Paraná, currently with 163 active employees, 75 on the directly nursing care area, divided into 14 nurses, 58 nurse technicians, and 3 nurse assistants. In the data collect was used the historical about the occupational accidents and information's provided by the company about the accidents, and quiz applied to employees for the collection of additional data about the accidents, in tried to identification of factors and processes involved. In the results found through quiz, we find notes about the stress and tiredness resulting of double workload, something common in the nurse professional category, beyond argumentation of low salary of the majority of professionals consulted.
\end{abstract}

KEYWORDS: Occupational accidents. Organizational environment. Nursing. 


\section{REFERÊNCIAS}

BOLICK D. et al., Segurança e controle de infecção. Rio de Janeiro (RJ): Reichmann\& Affonso - 1a edição; 2000.

ANVISA, Resolução RDC no 306, de 7 de dezembro de 2004. Dispõe o "Regulamento Técnico para o gerenciamento de resíduos de serviço de saúde". Órgão Emissor: ANVISA - Agência Nacional de Vigilância Sanitária. Dísponível em: portal.anvisa.gov.br. Acesso em: 22 de novembro de 2017.

CAMARGO Wellington, Gestão da Segurança do Trabalho, Instituto Federal do Paraná - Curitiba, 2011.

CHIAVENATO Idalberto, Gestão de Pessoas: o novo papel dos recursos humanos nas organizações, Elsevier - 3a Edição, 2008.

COSTA Denize Dalla, 0 estresse do administrador de empresas privadas: um estudo em Cascavel - PR, Universidade Católica Dom Bosco, Campo Grande, MS, 2006.

GIL Antonio Carlos, Métodos e técnicas de pesquisa social, São Paulo, Atlas - 6ạ edição, 2008.

HINRICHSEN Sylvia Lemos et al., Biossegurança e Controle de infecções - Risco Sanitário Hospitalar, Medsi, 2004.

LAKATOS Eva Maria, MARCONI Marina de Andrade, Fundamentos da metodologia científica, Atlas - 5a edição, 2003.

LAURELl Asa Cristina, NORIEGA Mariano, Processo de Produção e Saúde: trabalho e desgaste operário. Tradução: COHN Amélia et al. São Paulo, HUCITEC, 1989.

MTE. Ministério do Trabalho e Emprego, Portaria no 939, de 18 de Novembro de 2008, MTE - Ministério do Trabalho e Emprego. Disponível em www.trtsp.jus.br, Acesso em 22 de Novembro de 2017.

MTE. Ministério do Trabalho e Emprego, Portaria no 1748, de 30 de Agosto de 2011, MTE - Ministério do Trabalho e Emprego. Disponível em www.trtsp.jus.br, Acesso em 22 de Novembro de 2017. 
Segurança e Medicina do Trabalho, NR 01 à 33, São Paulo, Atlas - 64ạ edição, 2009.

BARBOSA, R.A.; AHRENS, R.B. Análise dos fatores relacionados aos acidentes de trabalho com perfuro cortantes em uma instituição hospitalar. R. Gest. Industr., Ponta Grossa, v. 14, n.4, p.87-102, out./dez. 2018. Disponível em: shttps://periodicos.utfpr.edu.br/rgi>. Acesso em: XXX.

Correspondência:

Rodrigo Abreu Barbosa

Rua Constantino Borsato, 445, Bairro Uvaranas, Ponta Grossa, Paraná, Brasil.

Direito autoral: Este artigo está licenciado sob os termos da Licença Creative Commons-Atribuição 4.0 Internacional.

\section{(c) (1)}

